\title{
"Las migraciones son como el agua": Hacia la instauración de políticas de "control con rostro humano". La gobernabilidad migratoria en la Argentina ${ }^{1}$
}

\author{
Eduardo Domenech \\ Universidad Nacional de Córdoba, Córdoba, Argentina. \\ Email: eduardo.domenech@gmail.com
}

Resumen: El artículo explora el proceso de transnacionalización de la política migratoria y la incidencia que ha tenido la emergente perspectiva de la gobernabilidad migratoria en el desarrollo de la "nueva política migratoria" en la Argentina. Se sostiene que su adopción en los organismos del Estado especializados en la migración ha sido decisiva para la configuración de ciertos cambios en los modos de pensar y actuar sobre la llamada "inmigración irregular". Se propone la noción de políticas de "control con rostro humano" para dilucidar nuevas formas de control de las migraciones y las fronteras internacionales. A través del análisis del concepto de migración ordenada, ingresada al ámbito de gobierno de la migración con la emergencia de un nuevo régimen global de control, se pretende contribuir a la comprensión del origen y fundamento de algunos desplazamientos en las formas de pensar y ejercer el control de las migraciones internacionales en la Argentina actual.

Palabras clave: migraciones, control, derechos humanos, política migratoria, Argentina.

\section{Migration are like water": Towards establishing "control with a human face" policies. The governance of migration in Argentina}

Abstract: The article explores the process of transnationalization of migration policy and the impact that has had the emerging migration governance perspective in the development of the "new immigration policy" in Argentina. It is argued that its adoption by State agencies specializing in migration has been instrumental in the setting of certain changes in the ways of thinking and acting about the "irregular immigration". The article proposes the notion of "control with a human face" policies in order to elucidate new forms of migration control and the international borders. Through the analysis of the concept of orderly migration, which entered the field of migration governance with the emergence of a new global regime of control, we intend to contribute to understanding the origin and foundation of some shifts in thinking and exercising international migration control in Argentina today.

Key words: migrations, control, human rights, migration policy, Argentina. 


\section{“A migração é como a água”: Rumo a criação política "controle com uma face humana". A governança da migração na Argentina}

Resumo: Este artigo analisa o processo de transnacionalização da política de migração e o impacto que teve a perspectiva emergente de governança da migração no desenvolvimento da "nova política de imigração" na Argentina. Argumenta-se que a sua adoção em órgãos estaduais especializadas em migração tem sido fundamental para a definição de algumas mudanças nas formas de pensar e agir sobre a "imigração ilegal". A política propõe a noção de "controlo com um rosto humano” para elucidar novas formas de controle de migração e fronteiras internacionais. Através da análise do conceito de migração ordenada, entrada no campo da governança da migração com o surgimento de um novo regime global de controle, busca-se contribuir para a compreensão da origem e fundação de algumas mudanças no pensar e exercer o controle da migração internacional na Argentina hoje.

Palavras-chave: migração, controle, direitos humanos, política de imigração, Argentina

$$
* * *
$$

\section{Introducción}

La atroz espectacularidad de las políticas de control desarrolladas en el marco de las migraciones mundiales de orientación Sur-Norte pareciera invisibilizar aquellas que se despliegan en contextos regionales de migración Sur-Sur donde se desenvuelven controles más sutiles y, quizás por ello, menos perceptibles. El discurso político sobre las migraciones internacionales ha comenzado a manifestar en distintos países sudamericanos algunas transformaciones significativas. Diversos Estados han impulsado o están impulsando una serie de reformas en materia de legislación y política migratoria que han colocado a los derechos humanos de los migrantes como uno de los principales fundamentos de los cambios iniciados o requeridos, otorgándole a la "ilegalidad" o "irregularidad" un lugar destacado en sus lineamientos de política. Una variedad importante de estas iniciativas encuentran su sustento ideológico en la perspectiva de la llamada gobernabilidad migratoria, adoptada y resignificada según las particularidades de cada contexto político nacional. En este sentido, la experiencia argentina, constituida en un caso paradigmático, no es posible comprenderla cabalmente sin considerar los efectos que ha tenido y tiene la regionalización de la política migratoria como parte de un proceso global de transnacionalización de la política de migraciones internacionales, impulsado por agencias multilaterales como la Organización Internacional para las Migraciones (OIM) y diversas instituciones de Naciones Unidas, cuyo resultado más notorio es la conformación de un régimen global de control migratorio.

El análisis, basado principalmente en una exhaustiva revisión de documentos oficiales (tanto internacionales como nacionales) e interven- 
ciones públicas de funcionarios del gobierno argentino (en particular, de la Dirección Nacional de Migraciones) entre los años 2000 y 2010, pretende mostrar que la perspectiva de la gobernabilidad migratoria constituye la visión de Estado ${ }^{2}$ que rige los lineamientos de la política migratoria instaurada en la Argentina a partir de la aprobación de una nueva ley de migraciones en el año 2003. En este sentido, sugiero que su influencia ha sido decisiva en la estructuración de ciertas ideas y prácticas estatales destinadas a regular la inmigración y, en particular, la llamada "inmigración irregular”. Bajo la cobertura ideológica de esta nueva perspectiva técnicopolítica se desarrolla una política de control con rostro humano: amparado en el discurso de los derechos humanos para obtener la legitimidad necesaria para su instrumentación, el control sobre la inmigración irregular desplaza (no elimina) formas restrictivas o coercitivas, pero no con el propósito de hacer efectivos los derechos humanos de los inmigrantes, sino para obtener mayores resultados en la administración eficaz de los flujos migratorios. Como sugiere Mezzadra en relación al régimen global de gestión de la migración, "el poder se está reconfigurando, en un contexto en el que la lógica de la soberanía se entrelaza con la lógica de la gobernabilidad neoliberal, con una gobernanza que se presenta como un sencillo proceso de persuasión sin coerción, según patrones neutros de cálculo y gestión de riesgos” (Mezzadra, 2012:169).

Utilizo la noción de políticas de control con rostro humano para referirme al universo de ideas y prácticas que, enmarcadas en el discurso de los derechos humanos como fuente de legitimación, persiguen la misma finalidad que las políticas más abiertamente restrictivas, prometiendo ser más eficaces en la consecución de su objetivo: controlar los flujos migratorios internacionales. El pensamiento tecnocrático parece haber encontrado en el control con rostro humano la fórmula largamente buscada para conciliar la lógica estatocéntrica de la soberanía nacional con el imperativo universalista abstracto de los derechos humanos. La figura del "control con rostro humano" podría ayudar a pensar y analizar las transformaciones actuales en materia de política de migraciones internacionales por fuera de la dicotomía derechos humanos versus seguridad. Una aproximación que relacione ambas categorías, junto con la noción de "desarrollo", permitiría comprender determinadas prácticas estatales y no estatales como nuevas formas de control de las migraciones y las fronteras internacionales, inscriptas en el nuevo régimen global de control de las migraciones entendido por Düvell (2003) como "globalización del control migratorio"que promueven actualmente organismos supranacionales como la Organización Internacional para las Migraciones (OIM). Esto llevaría también a descartar la idea de que se trata de experiencias nacionales aisladas o inéditas contrapuestas a las tendencias internacionales de fortalecimiento de los controles fronterizos. ${ }^{3}$ En este sentido, no suscribo la idea de que la perspectiva del migration management $t^{4}$ o gobernabilidad migratoria supone una vía alternativa a la securitización de la migración, sino que ambas actúan imbricada o complementariamente en el presente momento histórico del capitalismo global. Es decir, las políticas de control con rostro humano integrarían el actual régimen global de control de las migraciones, 
cuyo despliegue también supone formas de regulación restrictivas, coercitivas y punitivas. Por otro lado, en términos analíticos, buena parte de la dificultad para dilucidar críticamente la configuración de dicho régimen de control migratorio y su extensión en el mundo radica en que tanto entidades nacionales como supranacionales que proclaman la importancia de la protección y defensa de los derechos de los migrantes justifican y validan al mismo tiempo, por acción u omisión, las medidas selectivas de visado, los rechazos en frontera, el uso de la biometría en los controles de ingreso y permanencia, los centros de internamiento de extranjeros y las deportaciones o expulsiones.

\section{La migración ordenada como misión: hacia un régimen global de control de las migraciones internacionales}

Surgida en los años setenta con los informes de la Trilateral Commission, difundida en los ochenta por el Banco Mundial y retomada en los noventa por las Naciones Unidas a instancias del gobierno sueco, la noción de gobernabilidad comenzó a aparecer en el terreno de las migraciones promovida, principalmente, por la OIM en un contexto de profundas transformaciones en el orden internacional y el ingreso de las migraciones internacionales entre los asuntos políticos de mayor relevancia mundial. También en esta década, la denominada "inmigración ilegal” se incorporó a la agenda de la Unión Europea, la OCDE, la OIM y muchas otras agencias y se colocó a la cabeza de las preocupaciones de política internacional junto al comercio de armas, el tráfico de drogas y el crimen organizado, al mismo tiempo que el "combate a la inmigración ilegal” se extendió a otros terrenos de políticas como la ayuda al desarrollo, el comercio y las relaciones internacionales en general (Düvell, 2008). A unos años de celebrada la Conferencia de El Cairo, en 1999 tuvo lugar en Bangkok, Tailandia, un simposio internacional destinado a establecer acuerdos en materia de “migración irregular” (International Symposium on Migration "Towards Regional Cooperation on Irregular/Undocumented Migration”, 21-23 abril, 1999). El documento resultante de aquella reunión, la Declaración de Bangkok sobre Migración Irregular, ya contenía muchas de las ideas que luego se encontrarán plasmadas en las recomendaciones y lineamientos de política que se propondrán en los distintos espacios multilaterales que tendrán lugar en la década siguiente. Allí se señalaba la necesidad de contemplar la migración y en particular la "migración irregular”, considerando sus causas, manifestaciones y efectos, tanto positivos como negativos, en los países de origen, tránsito y destino. Con ello se pretendía encaminar las acciones a alcanzar los beneficios de la migración regular y reducir los costos de la migración irregular. Identificados los puntos salientes, orientados por la noción de “manejo ordenado de la migración”, se buscó ofrecer un conjunto de recomendaciones para "prevenir" y "combatir” la migración irregular y el tráfico de personas o, en otras palabras, "resolver el problema de la migración ilegal y del tráfico de personas”, especialmente mujeres y niños. 
A principios de la primera década del siglo XXI, las migraciones, en particular las "migraciones irregulares”, ya habían alcanzado un lugar prominente en la agenda mundial. En pocos años las "migraciones irregulares", otrora llamadas "ilegales", se convirtieron en uno de los asuntos mundiales que mayor atención empezó a recibir, especialmente después de los acontecimientos del 11-S. En el año 2002, el secretario general de las Naciones Unidas, Kofi Annan, identificó la inmigración como un hecho de acción prioritaria a escala global (López Sala, 2005). Al año siguiente se formó la Comisión Global sobre Migraciones Internacionales (GCIM, por sus siglas en inglés), que tuvo entre sus principales preocupaciones las “migraciones irregulares”. Luego, en el año 2004, la cuestión de la migración irregular irrumpía en el Parlamento Europeo. Allí, el secretario general de Naciones Unidas planteó la necesidad de desplegar acciones conjuntas para enfrentarla (López Sala, 2005). Calificó a la "inmigración irregular" como "un problema real” y señaló la necesidad de que los Estados se abocaran a detenerla. Concluida la tarea encomendada a la GCIM en el 2005, al año siguiente, se realizó un evento mundial, promovido por las Naciones Unidas, destinado específicamente a tratar la temática de las migraciones: el Diálogo de Alto Nivel sobre Migración y Desarrollo. Poco tiempo después, el secretario general de las Naciones Unidas, en el acto inaugural de la XVI Cumbre Iberoamericana, al mismo tiempo que señalaba que la migración internacional era "uno de los problemas centrales de este siglo”, atribuyendo su escalada al proceso de globalización y las transformaciones en el ámbito del transporte y las comunicaciones, expresaba que la migración, mientras fuera adecuadamente administrada, podía y debía ser un factor positivo para el desarrollo de las sociedades de origen y destino. Con la crisis financiera global desataca en el 2008, como indica Santi (2011), el reclamo por un orden que propicie el control de los movimientos poblacionales se vio fortalecido.

A esta altura, la "migración irregular", junto al comercio de armas, el tráfico de drogas y el crimen organizado, ya estaba considerada entre las "nuevas amenazas mundiales". En los años previos a la crisis financiera global, los diagnósticos realizados por instituciones supranacionales, consultores internacionales y académicos asociados a reconocidos centros de investigación y think tanks (en muchos casos, actuando como voceros de diversas agencias globales) convinieron en que se trataba de un estado de desgobernabilidad o crisis migratoria. En América Latina, esta desgobernabilidad migratoria (Mármora, 2002) se habría producido por los cambios en los patrones migratorios internacionales durante la década de los noventa y las dificultades de los Estados para darles respuesta, motivando distintas acciones bi y multilaterales a través de espacios de integración subregional y la formación de procesos consultivos especializados en la temática migratoria (Mármora, 2003). Entre los aspectos que compondrían esta crisis, Mármora apunta "el aumento de la irregularidad migratoria, el incremento de las situaciones de xenofobia y discriminación, el aumento del negocio de las migraciones, la incongruencia entre políticas migratorias y los espacios regionales de integración económica, los problemas de relaciones bilaterales entre países con flujos migratorios fronterizos, y la rup- 
tura de la funcionalidad de las políticas migratorias en relación con los requerimientos de mano de obra y de recambio poblacional” (Mármora, 2004:3). En otra parte, ha señalado específicamente el "incremento de migrantes en situación irregular" y los "mecanismos de tráfico e introducción clandestina de personas asociados a este fenómeno" como ejemplos ilustrativos de los “problemas de gobernabilidad existentes” (Mármora, 2002:46). Descartada la posibilidad de utilizar medidas unilaterales, la superación de esta crisis requeriría de modalidades bi y multilaterales que permitan alcanzar los acuerdos regionales necesarios en materia de políticas migratorias que favorezcan la gobernabilidad de los flujos migratorios internacionales. Actores institucionales como la OIM y la CEPAL, como se reconoce en los propios documentos de políticas de estos organismos, han colaborado "estrechamente en la consolidación de estas iniciativas orientadas a la gobernabilidad de la migración internacional” en la región (Martínez Pizarro, 2001:16).

Los llamados procesos consultivos regionales surgidos en los últimos años, como la Conferencia Sudamericana sobre Migraciones, cuya Secretaría Técnica es ejercida por la OIM, y los foros especializados en migraciones de los bloques regionales de integración económica como el Mercosur y la CAN, tienen entre sus objetivos principales no sólo definir una posición común en el tema migratorio frente a otros interlocutores nacionales o internacionales, sino también fijar lineamientos para la elaboración de políticas nacionales en materia de migraciones. ${ }^{5}$ En la constitución del nuevo régimen internacional para el movimiento ordenado de personas, como lo llama uno de sus ideólogos, Bimal Ghosh, los foros consultivos regionales contribuirían, según se establece en un informe reciente de la OIM, a) construyendo confianza entre los Estados e incrementando el entendimiento sobre los asuntos migratorios; b) derribando divisiones entre Estados y entre diferentes departamentos de gobierno en su interior, creando redes y facilitando la armonización de posiciones a través de las regiones; y c) edificando capacidad y haciendo efectivos los cambios a través de leyes, políticas o prácticas (Hansen, 2010). ${ }^{6}$ Estos espacios regionales son la cristalización de procesos y proyectos de más amplio alcance. Iniciados la mayoría de ellos hacia mediados de la década de los noventa, especialmente a partir de la Conferencia Internacional sobre la Población y el Desarrollo realizada en El Cairo en 1994 y su plan de acción, los procesos consultivos regionales surgieron frente a la constatación de que los Estados no pueden manejar la migración de manera unilateral (Hansen, 2010). ${ }^{7}$ La interrelación entre estos procesos consultivos regionales especializados en migraciones y la aparición de los espacios intergubernamentales como la Iniciativa de Berna, la Comisión Global sobre Migraciones Internacionales y el Grupo Mundial sobre Migración (GMG, abreviado en inglés) a comienzos de la presente década, junto a otros espacios multilaterales de carácter intergubernamental más recientes como el Foro Global sobre Migración y Desarrollo (después que se recomendara su creación en el Diálogo de Alto Nivel sobre Migraciones convocado por Naciones Unidas un año antes), ha permitido avanzar en la construcción y consolidación de una serie de consensos acerca de los modos adecuados de ad- 
ministrar, gestionar o gobernar la migración a escala global, dando lugar a un régimen global sobre las migraciones internacionales.

Una de las expresiones de este nuevo régimen internacional destinado a regular los flujos migratorios internacionales, como he señalado en anteriores ocasiones (Domenech 2007, 2008), ha sido la emergencia de una agenda política global promovida y liderada por organismos internacionales ya consolidados en el orden mundial como la OIM y diversas agencias de Naciones Unidas, la cual sería producto del consenso obtenido entre actores del sistema internacional. ${ }^{8}$ Las instituciones que lideran esta emergente agenda global, las cuales forman parte de las estructuras hegemónicas del sistema mundial (Guimarães, 2005), disponen de una producción y sistematización de conocimiento y experiencias mundiales y de una extensa red de vínculos con organismos gubernamentales, think tanks, instituciones académicas y centros de investigación, organizaciones de la sociedad civil y del sector privado y medios de comunicación masivos, además de las organizaciones supraestatales regionales o internacionales asociadas, que les permiten llevar adelante su proyecto político y les confieren al menos la base de su legitimación. ${ }^{9}$ En este sentido, el régimen global de gestión de la migración, como indica Mezzadra, no refiere a un “gobierno político integrado", sino más bien a "la formación contradictoria y fragmentaria de un cuerpo de conocimientos dentro de comunidades políticas y epistémicas dispares” (Mezzadra, 2012:169).

Como muestran los catorce procesos consultivos regionales desarrollados a nivel mundial con el apoyo técnico-político de la OIM, no se trata necesariamente de una visión integral ni unívoca. Su desarrollo difiere según los intereses de los actores políticos implicados y las especificidades del contexto sociohistórico. Tampoco se trata de lineamientos impuestos de manera unilateral por los organismos internacionales o adoptados mecánicamente por los Estados nacionales: aunque ciertas agencias internacionales ejercen una innegable influencia en la construcción de las agendas políticas nacionales, también es cierto que la agenda global se construye a partir de casos nacionales considerados “exitosos” que a la vez sirven para mostrar y recomendar a otros Estados las llamadas “buenas prácticas”. ${ }^{10}$ Además, si bien las iniciativas y medidas estatales pueden responder a recomendaciones y exigencias de organismos internacionales (las cuales son también producto de compromisos estatales asumidos en acuerdos regionales y en reuniones mundiales ${ }^{11}$ ) y el rol de los Estados nacionales se ha visto modificado en la arena política internacional, donde la disputa por la producción de sentido, prácticas y políticas se ha complejizado, aquéllos mantienen su poder de decisión sobre los asuntos migratorios. Más aún, la conformación de este régimen global sobre las migraciones internacionales supone la participación de los Estados nacionales como socios activos de los organismos internacionales que lo impulsan.

La misión institucional de la OIM con la cual se consagra al principio de que "una migración ordenada y en condiciones humanas beneficia a los migrantes y a la sociedad” ha pasado a formar parte de la visión que 
sostienen todos aquellos actores comprometidos con el "nuevo régimen internacional para la migración ordenada de personas”. Como ya he señalado en otros lugares (Domenech 2007, 2008), con la paulatina instauración de este régimen ha surgido una nueva manera de organizar, clasificar y controlar los movimientos internacionales de población. Desde esta perspectiva, basada en las nociones de equilibrio y eficacia y en una lógica de costo-beneficio -encarnada en la figura del balance contable ${ }^{12}$ aplicado a la inmigración (Sayad, 1998)- pragmática y utilitarista, que advierte la imposibilidad de controlar eficazmente a través de medidas de índole restrictiva a los flujos migratorios, especialmente aquellos de carácter irregular, los migrantes son clasificados sobre la base de una supuesta (in)utilidad, estableciendo una serie de ventajas o beneficios y desventajas o perjuicios (no sólo económicos) de la inmigración. Como lo destaca el conocido lema de la OIM, Managing Migration for the Benefit of All, desde esta perspectiva se propone que la migración, administrada adecuadamente, puede beneficiar tanto a las sociedades de origen y destino como a los migrantes.

Asumiendo que la migración posee en sí misma o intrínsecamente propiedades o consecuencias positivas o negativas, cuando no son más que un recurso de argumentación política, la legitimidad o ilegitimidad de la presencia inmigrante queda sujeta y se termina dirimiendo entre los "beneficios” y los “costos” que la inmigración -siempre según la perspectiva e intereses del Estado nacional como representante de lo universal- traería aparejada. Así, la construcción de la figura social del inmigrante queda signada por una visión dualista que lo concibe en términos negativos o positivos, ya sea atribuyéndole la responsabilidad de los problemas sociales o económicos del país, ya sea rescatando su contribución al crecimiento económico o su aporte al “enriquecimiento cultural”. Pareciera que los inmigrantes sólo pueden ser aceptados cuando su presencia lo amerita: siempre y cuando constituyan una contribución, un aporte o una ventaja para las sociedades en las cuales decidieron desarrollar sus vidas. Esta visión promueve la idea de que la presencia es legítima en tanto sus efectos sean "positivos" o ilegítima en tanto sean "negativos” para las sociedades de inmigración o emigración. En otras palabras, la presencia del inmigrante sólo es considerada legítima mientras deje un “saldo positivo” para la sociedad receptora. Y para ello, la migración, como sostiene la nueva ortodoxia en la materia, debería ser “ordenada”, es decir, libre (o liberada) de migraciones “ilegales” o "irregulares”.

Desde la perspectiva de la gobernabilidad migratoria, los flujos migratorios son clasificados en deseables e indeseables de acuerdo a su carácter ordenado/desordenado, voluntario/forzoso y reducido/masivo, desplazando -en tanto enfoque global- los criterios étnico-nacionales que históricamente han distinguido la aplicación de las políticas migratorias selectivas y las definiciones tradicionales sobre el control migratorio. De ello se deriva un "excedente de movilidad” (Mezzadra, 2012) que, bajo la perspectiva de la gobernabilidad migratoria, es identificado como objeto de control y vigilancia. Precisamente, al margen de las distintas apropiaciones que esta perspectiva pueda tener, uno de los aspectos centrales que 
hace a su propia definición es la noción de frontera que maneja. Andrijasevic y Walters (2010), en su análisis de la OIM y su involucramiento en lo que llaman el "gobierno internacional de las fronteras", sostienen que los límites políticos internacionales no son vistos como instrumentos geomilitares que sirvan de contenedores de la población y el territorio, sino como mecanismos privilegiados que permitan regular, en un mundo aún segmentado jurídica y políticamente en espacios nacionales, el modo en que los procesos migratorios globales tengan lugar.

En las ediciones de la Conferencia Sudamericana sobre Migraciones (CSM), como señalan Ramírez Gallegos y Alfaro Aramayo (2010), las nociones de gestión y gobernabilidad de las migraciones han cobrado tal entidad que el foro ha llegado a ser definido como "una instancia regional para la concertación de estrategias regionales para la gobernabilidad de las migraciones internacionales” (V CSM, La Paz, 2004). También en las últimas reuniones los Estados acordaron la formación de una Red Sudamericana para la Gobernabilidad Migratoria (VIII CSM, Montevideo, 2008) y la aprobación del denominado Plan Sudamericano de Desarrollo Humano para las Migraciones (X CSM, Cochabamba, 2010), que sería el resultado de "una etapa de consensos donde las acciones específicas promovidas por la Conferencia se encuadran en un cuerpo de principios que los gobiernos asumen como su posición común de gobernabilidad migratoria” (PSDHM, 2010). Esta nueva propuesta y el plan de acción adoptado (por mandato de la II Reunión de Presidentes de América del Sur) durante la tercera CSM realizada en Quito en el año 2003 CSM, junto a sus posteriores revisiones, son una muestra concreta de la internalización de los criterios técnico-políticos que propone la perspectiva de la gobernabilidad migratoria. Como sugieren Andrijavisevic y Walters (2010), el plan de acción debe ser entendido como una técnica clave a través de la cual los gobiernos son construidos como agentes para reformar algunos ámbitos particulares de políticas, estableciendo una nueva relación entre los gobiernos, la comunidad internacional y el control de las fronteras estatales. Dos de los componentes centrales del plan de acción de la CSM, también implícitos en los principios, lineamientos estratégicos y acciones específicas del PSDHM, se relacionan con el "desarrollo de programas nacionales y binacionales de regularización migratoria” para las personas y familias migrantes y la "promoción de la integración e inserción de los migrantes” en los países de destino, cuyas metas y actividades apuntan a la implementación, con la participación de la OIM, de "un programa técnico para la identificación y cuantificación de migrantes irregulares en los países con mayor inmigración” y de "acuerdos recíprocos entre gobiernos" para la aplicación de procesos de regularización migratoria, acompañados con acciones que permitan producir "nuevos criterios" relativos a su diseño y puesta en práctica y difundir iniciativas gubernamentales que resalten "los beneficios que implica mantener una condición migratoria regular”. Como veremos más adelante, ambos componentes estructuran las argumentaciones y prácticas desarrolladas en el marco de la "nueva política migratoria" en la Argentina, especialmente con la implementación del programa de regularización migratoria conocido como "Patria Grande". 
Por otra parte, el concepto de migración ordenada como componente constitutivo de la perspectiva de la gobernabilidad migratoria atraviesa desde sus inicios el proceso consultivo regional sudamericano. Desde la primera edición en adelante, los Estados han señalado la conveniencia de promover "una migración ordenada y planificada como solución a la migración irregular y la lucha contra el tráfico de seres humanos”. Asimismo, en correspondencia con la mirada que propone la gobernabilidad migratoria sobre las fronteras y el modo de controlar los flujos migratorios internacionales, los Estados han declarado que "la aplicación de medidas restrictivas por los países de destino no constituye una solución realista a la emigración irregular” (VIII CSM, Montevideo, 2008). Dado que la perspectiva de la gobernablidad migratoria parte del supuesto de que una "migración ordenada” trae consigo innumerables beneficios, las declaraciones suelen resaltar los efectos positivos que tendría la inmigración y el aporte que harían los migrantes en el ámbito económico, social y cultural, omitiendo el político.

\section{La “nueva política migratoria” y los derechos humanos: el "cambio de paradigma” en la Argentina}

Los años previos a la sanción por unanimidad de la nueva ley de migraciones en diciembre de 2003 y su promulgación en enero de 2004, en particular el período transcurrido en el período 2000-2003, fueron decisivos en la gestación de la llamada “nueva política migratoria”, cuyos lineamientos se manifestarán más abiertamente hacia mediados de la década. Estos años fueron de una intensa labor legislativa, concentrada particularmente en la elaboración y discusión de la nueva ley migratoria. Pero no sólo fue importante el proceso de negociación que se dio al interior del Poder Legislativo, sino también la posición que asumieron los distintos organismos del Poder Ejecutivo -en particular, el Ministerio del Interior a través de la DNM- frente a la cuestión migratoria en medio de diferentes administraciones gubernamentales. A partir de inicios de la década comienza a delinearse una visión sobre las migraciones internacionales que más adelante encontrará su correlato en las directrices de la "nueva política migratoria” y en los argumentos oficiales ofrecidos, especialmente desde la sanción de la "nueva ley de migraciones": ya en el año 2000, luego de la embestida oficial contra los inmigrantes limítrofes -en particular la "inmigración ilegal” y los “inmigrantes ilegales”- durante el último año de gobierno de Menem y el rechazo generalizado que provocó en diversos sectores de la sociedad civil (asociaciones de inmigrantes, organizaciones de derechos humanos, instituciones de la iglesia católica y académicos fundamentalmente), altos funcionarios de organismos del Estado, aunque contradichos por la persistencia de prácticas restrictivas y arbitrarias en el seno de organismos de la administración pública como el Ministerio del Interior $^{13}$, procuraron mostrar una posición aperturista frente a los inmigrantes de países limítrofes con referencias explícitas a la importancia de respetar y proteger los derechos humanos de los inmigrantes. 
Más adelante, a partir del año 2004, con la asunción de Ricardo Rodríguez como nuevo director de la DNM y ya aprobada la nueva ley de migraciones por el Congreso Nacional, diversos funcionarios de alto rango de la institución y, en menor medida, de otros organismos del Poder Ejecutivo, comenzaron a difundir y explicar las medidas que estaban llevando adelante en materia de política de migraciones en distintos eventos nacionales e internacionales. Estas medidas inspiradas en la "nueva ley de migraciones” y reunidas bajo la denominación de "nueva política migratoria”, responderían a una nueva perspectiva ${ }^{14}$ sobre los asuntos migratorios, que en algunas intervenciones y documentos oficiales es caracterizada como un "nuevo paradigma" ${ }^{15}$, inscripta ya en algunos espacios del orden internacional y regional en los cuales la noción de gobernabilidad migratoria tuvo una importante acogida: el enfoque de los derechos humanos. ${ }^{16}$ Según la visión de los funcionarios estatales, el actual escenario de las migraciones internacionales intra y extrarregionales requería del Estado un "cambio de paradigma”, concebido como un desplazamiento desde el enfoque estatocéntrico de la seguridad y control de fronteras hacia una perspectiva integral de derechos humanos, en la cual el migrante y su familia fueran el objeto principal de las intervenciones de gobierno. Este "nuevo paradigma” o "cambio de paradigma" relativo a las migraciones internacionales habría sido adoptado con la "nueva política migratoria” del Estado argentino -plasmado en el "espíritu de su política migratoria"- y se habría materializado en dos instrumentos centrales: la ley de migraciones y el programa nacional de regularización migratoria. Según el planteo subyacente a los diversos documentos oficiales e intervenciones públicas de los funcionarios, la "nueva política migratoria” sería la concreción del paso de un enfoque basado en los principios de seguridad y control a otro fundado en el precepto de los derechos humanos, presentados como perspectivas antagónicas y mutuamente excluyentes. En este proceso, la perspectiva del control y la seguridad, colocada en el pasado, habría sido reemplazada por la perspectiva de los derechos humanos, en plena vigencia, acentuando de este modo, la idea de ruptura entre ambos sistemas de pensamiento y acción, en particular cuando se considera el cambio en términos de "paradigma”. Así, siguiendo el argumento oficial, lo nuevo de la "nueva política migratoria" sería el cambio de enfoque adoptado, sustentado en los derechos humanos. De acuerdo a ello se postula un "giro diametral" en materia de política migratoria y se presenta la postura del Estado argentino como una "posición de avanzada" en relación a la protección de los derechos de los migrantes. Para dar cuenta de este cambio de paradigma o enfoque, los documentos oficiales de política migratoria, especialmente cuando se trata de documentos presentados en el ámbito internacional, suelen enunciar las distintas convenciones internacionales referidas a la protección de los derechos humanos en general y de los derechos de los inmigrantes en particular, especialmente la Convención Internacional sobre la Protección de los Derechos de Todos los Trabajadores Migratorios y de sus Familiares de Naciones Unidas. En términos de medidas políticas, las distintas perspectivas son caracterizadas de acuerdo a los criterios de admisión y permanencia que una y otra supondrían, contraponiendo un modelo basado en una noción restrictiva y punitiva de la migración frente a otro fundado en las 
ideas de integración e inserción asentadas en los derechos humanos.

Aunque rara vez haya sido expresado públicamente por los altos funcionarios de la DNM, este nuevo paradigma o modelo que se propugna actualmente en la Argentina en materia de política migratoria no es otro que la perspectiva de la gobernabilidad migratoria. ${ }^{17}$ Según los recuerdos y percepciones de un funcionario de planta permanente de la DNM y con una extensa trayectoria en el organismo, las migraciones internacionales habrían empezado a ser vistas de una manera diferente desde el Estado alrededor del año 2002. ${ }^{18}$ Con el paso de la "doctrina del control” a la “doctrina de la gobernabilidad de los procesos migratorios” se habría adoptado en el seno del Estado nacional (o mejor dicho, en determinados ámbitos del Estado nacional) un “discurso más equilibrado”. ${ }^{19}$ Dicho en términos conceptuales, la introducción de la perspectiva de gobernabilidad migratoria sería producto de un proceso de “maduración” y “enraizado"20 en la órbita del Estado que comenzó a gestarse algunas décadas atrás mediante la concurrencia de diversos actores sociales y políticos. Para él, hubo "todo un proceso que en algún momento a los tomadores de decisiones políticas les llegó un discurso, o una propuesta o una articulación entre lo operativo, lo normativo y lo político diferente”. Fue allí que "empezó a haber el discurso que antes no lo había”. Este “proceso político”, según sus palabras, se produjo gracias a la participación de "muchos actores que han influido con su pensamiento" -entre los que menciona organismos internacionales como la OIM y organismos de la sociedad civil involucrados con el "desarrollo de la idea de los derechos humanos”- y al “desarrollo conceptual y teórico del tema que no teníamos”. En este sentido, destaca la influencia que tuvieron los cursos de capacitación de la OIM, iniciados a principios de la década del `80, sobre los actuales “tomadores de decisiones”. Se trataba de "un discurso diferente de los técnicos de principios de los `80, cuando yo empecé a trabajar en Migraciones”. A través de estos cursos, la OIM habría formado un buen número de "los que hoy están en posiciones dirigenciales en los países de la región”. ${ }^{21}$ Para él, este espacio de capacitación de funcionarios de gobierno era una "caldera de pensamiento, de discusión” de la cual provinieron ideas que arraigaron en determinados "círculos” sociales y políticos hasta permear los "niveles de toma de decisiones” del Estado. ${ }^{22}$ Considera en relación a los cambios en la política migratoria argentina que “(m)uchas de esas ideas han surgido de ahí". Esta influencia de la OIM sobre la política nacional no se habría ejercido a través de mecanismos de “imposición” de tipo compulsivo (¿` extorsivo?) como la del Banco Mundial, sino mediante mecanismos que Dale (1999) identifica como "diseminación”.23

Sin que formara parte de la agenda de gobierno, es a partir de la sanción de la nueva ley de migraciones -como expresión de distintos intereses y diversas fuerzas sociales y políticas- que el Estado nacional incorporó como un aspecto constitutivo de su discurso la temática de los derechos humanos de los inmigrantes. Ciertamente, el hecho de que encontrara resonancia en el Estado y resultara viable su desarrollo en el tiempo se explica, en alguna medida, por el contexto inmediato en el cual se inauguró 
y llevó adelante la "nueva política migratoria”. Sin embargo, diversos indicios señalan la importancia que tiene el proceso de transnacionalización de la política migratoria en la constitución de la "nueva política migratoria” y la emergencia del consecuente "cambio de paradigma" o la renovada visión que empezó a arraigarse en los organismos del Estado argentino especializados en la temática poblacional y migratoria: la aparición del tema de los derechos humanos en el terreno de las migraciones en el contexto argentino se relaciona principalmente con la penetración de la gobernabilidad migratoria en los ámbitos de gobierno de las migraciones. Como observan Geiger y Pécoud (2010), los derechos humanos tienen un rol central, aunque ambivalente, en el despliegue del migration management, posibilitando la construcción de entendimientos comunes. De allí el habitual énfasis en la necesidad de respetar los derechos humanos de los migrantes y las constantes referencias a las convenciones internacionales que servirían para dicho propósito. Precisamente, una de las tesis centrales de uno de los ideólogos del "nuevo régimen internacional para el movimiento ordenado de personas”, Bimal Ghosh, es que la protección de los derechos humanos de los migrantes y la administración efectiva de la migración -asegurar que la migración sea ordenada y predecible y, en consecuencia, más manejable- están estrechamente interrelacionados; dicho nexo sería el "eslabón perdido” (Ghosh, 2008). Por su parte, Mármora (2002), uno de los mayores propulsores de la gobernabilidad migratoria en América Latina, buscando operacionalizar dicha perspectiva, señala la importancia que posee el cumplimiento de los acuerdos y normas nacionales e internacionales, así como su coherencia y consecuencia con los principios y valores aceptados universalmente, para que la gobernabilidad migratoria obtenga la legitimidad necesaria de los migrantes. Pero además de ello, es muy esclarecedor reparar en el lugar que se le asigna a la protección de los derechos humanos de los migrantes: desde esta perspectiva, su defensa resulta relevante en la medida que la violación de los derechos humanos provocaría "flujos migratorios desordenados y no deseados", al mismo tiempo que el carácter "desordenado" y "no deseado" de estos movimientos supondría un riesgo mayor de violación de los derechos humanos. Todo ello conduciría a que la “administración de la migración” se haga "más difícil y costosa, tanto en términos humanos como financieros” (Ghosh, 2008:50).

\section{Migración ordenada, migración irregular: los "inmigrantes ilegales" como problema}

Erigida como una construcción específica del siglo veinte (Düvell, 2008) resultante de la monopolización estatal de los medios legítimos de movimiento (Torpey, 2000), la "migración ilegal”, aunque siempre sujeta al orden nacional, ha pasado a ser edificada y colocada en el nuevo orden global entre los principales cuestiones que atañen a la "comunidad internacional”, colaborando en su fabricación como una entidad social con existencia propia. Como señalé anteriormente, la idea de una migración ordenada, basada fundamentalmente en la legalidad de los flujos migratorios, 
es una de las premisas del nuevo régimen global de control de las migraciones internacionales. Según el propósito de convertir a la migración en un proceso más ordenado, predecible y manejable, además de hacerlo provechoso para todos los actores involucrados, el control de las ahora llamadas “migraciones irregulares” resulta fundamental. De ahí las recomendaciones a los Estados para implementar programas de gobierno que eviten las "migraciones irregulares" y busquen modos alternativos a las medidas restrictivas para enfrentarlas, entre ellas la promoción de programas de regularización migratoria. Ahora bien, aunque sea considerada una medida de excepción, entiendo que la regularización migratoria no corre por fuera, sino que forma parte del régimen de control instituido paulatinamente por los Estados para regular el ingreso, la permanencia y la expulsión de la población extranjera. Es decir, por más que la regularización migratoria se aleje de las convencionales medidas represivas, es posible entenderla como un mecanismo de control y vigilancia estatales para regular la inmigración en general y la construida como "ilegal" en particular.

En general, desde la perspectiva de la gobernabilidad migratoria, no se propone un esquema de control basado en el aumento de las restricciones (al menos no como principio), sino un modo de regulación que permita conducir, direccionar, canalizar los flujos migratorios. Asumidos los resultados conseguidos para controlar de manera eficaz las fronteras y la inmigración mediante políticas restrictivas como fracaso, desde la perspectiva de la gobernabilidad migratoria no se propone un esquema de control basado en el aumento de las restricciones (al menos no como principio). En cambio, se promueve encontrar estrategias de control más sutiles que permitan conducir, direccionar, canalizar los flujos migratorios. De ahí las recomendaciones a los Estados para implementar programas gubernamentales, que eviten las "migraciones irregulares" y busquen modos alternativos a las medidas restrictivas para enfrentarlas, entre ellas la promoción de programas de regularización migratoria. La idea de fracaso de las políticas restrictivas para el control efectivo de las fronteras y la inmigración admite, a la vez, que confirma la finalidad perseguida: se establece un cuestionamiento al medio utilizado por su falta de eficacia que deja intacto el fin establecido. La metáfora que ofrece el ex director de la DNM expresa de una manera elocuente la concepción sobre las migraciones y su control que subyace a la idea de gobernabilidad de los flujos migratorios como finalidad: las migraciones internacionales son como el agua. Dado que no se las puede detener, es necesario encauzarlas. ${ }^{24}$

En la Argentina, de modo consecuente con la importancia otorgada a la "migración ordenada" como objetivo político, la instrumentación de la "nueva política migratoria" ha estado supeditada y orientada a regular los flujos migratorios, en particular los llamados "irregulares", antes que a garantizar los derechos humanos de los inmigrantes contemplados en la nueva ley nacional de migraciones. Además de las reformas institucionales llevadas adelante para fortalecer la capacidad institucional de la DNM, siempre mantenida en la órbita del Ministerio del Interior, la "nueva política migratoria” estuvo centrada básicamente en el diseño y la implementación 
de un programa de regularización migratoria que, como innovación, adoptó una modalidad de tipo permanente (que más adelante se vería revisada). Esto muestra la principal preocupación del Estado: el diagnóstico oficial identifica la ilegalidad/irregularidad como el "mayor problema” que es preciso resolver en el orden de las migraciones, estableciéndose consecuentemente la "regularización migratoria” como la principal prioridad. En palabras del director de la DNM en aquél momento: "El mayor problema que tenemos respecto a las migraciones es el que hemos atacado primeramente porque creemos que es el más importante: los inmigrantes llamados, entre comillas, ilegales, que nosotros denominamos indocumentados”. ${ }^{25}$ En diversas ocasiones, algunos funcionarios han declarado que el desafío era encontrar una “solución” a la llamada “problemática de la irregularidad migratoria”, para lo cual necesitaban conocer "la raíz de la irregularidad”.

De acuerdo a la premisa de que las migraciones no pueden ser frenadas mediante mecanismos restrictivos y represivos, en el ámbito de gobierno de las migraciones se empieza a consolidar la idea de que es menester direccionar los flujos migratorios de acuerdo a las necesidades económicas del país, decir es, encauzar la mano de obra que proveen los inmigrantes hacia lugares geográficos de la Argentina donde resulte necesaria. De esta manera se evitaría, además, que los servicios públicos como los del sector salud no se saturen. Pero para llevar a cabo dicho proyecto se imponía antes un proceso de legalización que permitiera conocer e identificar este grupo poblacional. Durante su visita a la Cámara de Diputados de la Nación en el año 2004 para explicar los lineamientos de la política migratoria, el director de la DNM expresó algunos conceptos que más tarde reproducirá su sucesor con mayor claridad: es necesario potenciar los aspectos considerados positivos de la migración y disminuir los negativos para que con la presencia de los inmigrantes el país obtenga el mayor beneficio.

Así, el principal mecanismo que adoptará el Estado en el marco de la “nueva política migratoria” para regular las migraciones internacionales será un programa de regularización migratoria. Inscripto en la política que el Estado argentino promueve en el marco del Mercosur, el programa Patria Grande, como expresión del “cambio de paradigma” enunciado en materia migratoria, constituye la respuesta política a lo que el diagnóstico oficial identificara en años anteriores como el mayor y más importante "problema” que era preciso “atacar” en el orden de las migraciones: los “inmigrantes ilegales”, nombrados también como “indocumentados”. El programa fue presentado también en reuniones internacionales como la solución a la inmigración proveniente de países del Mercosur ampliado, los cuales constituyen el mayor volumen de migrantes que recepta la Argentina. Una definición que deja incólume la representación dominante acerca de las migraciones limítrofes en la Argentina: las migraciones regionales, en particular de los países vecinos, establecidas como equivalentes a las migraciones “ilegales” o "irregulares”, se constituyen en el "problema” que es preciso resolver, la "problemática” que es necesario atender. Más recientemente, también algunos grupos nacionales provenientes de la mi- 
gración extrarregional se han convertido en objeto de control de la "irregularidad migratoria”. Es su construcción como “ilegal” o "irregular” a manera de una esencia inherente a los inmigrantes lo que históricamente, a pesar de las variaciones que en materia de política ha habido, ha definido y constituido a las migraciones como "problema”, como un producto que crea "problemas". ${ }^{26}$ Es decir, más allá de las reformas enunciadas como producto de un cambio de paradigma o modelo, la inmigración persiste concebida como problema a partir de la "ilegalidad" o "irregularidad" que se le adscribe y la solución que se le antepone (la regularización postulada como instrumento de “integración”), dirimiéndose la legitimidad de la presencia del inmigrante entre los costos y los beneficios de una "inmigración ordenada”.

Es decir, los inmigrantes “ilegales”, ahora “irregulares”, como aquella fracción de población diferenciada producida por el propio Estado son los que a lo largo de las décadas y de las diversas políticas migratorias permanecen como el problema de la inmigración, el "problema a resolver". Las formas de nombrar y clasificar a los sujetos migrantes sospechados de mantener una relación conflictiva con el cumplimiento de la ley (clandestinos, ilegales, indocumentados, irregulares), sus eufemismos y su recurrencia en el tiempo, así como las acciones estatales destinadas a convertir los migrantes "ilegales” o "irregulares" en "legales”, han validado y perpetuado el campo de la "ilegalidad migratoria”. Como señala De Genova (2002), el carácter invariablemente parcial de los procesos de "legalización” o "regularización” nunca elimina el campo de la “ilegalidad”, sino que más bien refina y reconstituye ese campo para los que no resultan elegibles y permanecen indocumentados a la par de todas las posteriores llegadas “ilegales”. Las respuestas a la "ilegalidad migratoria” como los programas de regularización migratoria, cualquiera sea su modalidad, muestran la persistencia de fórmulas ancladas en una visión estatocéntrica de la migración. Bajo esta visión no sólo se mantiene naturalizada la división entre nacionales y extranjeros, buscando en el mejor de los casos cierta equiparación entre los derechos y obligaciones establecidos para cada uno en una sociedad democrática, sino que se vuelve impensable o impracticable la construcción de relaciones de igualdad entre los nacionales, considerados jurídicamente como ciudadanos, y los extranjeros que se encuentran en una situación administrativa irregular. Denota la falta de voluntad, imaginación o creatividad política para repensar y cuestionar la división legal/ilegal en un contexto regional políticamente propicio para implementar políticas de libre residencia -independientemente de las políticas de libre circulación de trabajadores en curso- que trasciendan la división legal/ilegal a la cual está supeditada cualquier visión de la migración que no pueda desprenderse del pensamiento de Estado. ${ }^{27}$ Colocarlos como sujetos en el lugar de la "ilegalidad” (o su equivalente "irregularidad”, término utilizado con aires de neutralidad, extirpándole la idea de “delito”, pero que no deja de ubicarlos en el lugar de la falta, el error, la infracción), como transgresores de las leyes del Estado, es uno de los modos más violentos de legitimar la desigualdad y la exclusión de quienes han sido producidos histórica y socialmente como sujetos indeseables. 


\section{Notas}

${ }^{1}$ Este texto constituye una versión revisada y aumentada del presentado en el IV Congreso de la Red Internacional de Migración y Desarrollo: "Crisis global y estrategias migratorias: hacia la redefinición de las políticas de movilidad”, celebrado en Quito, Ecuador, en el mes de mayo de 2011.

${ }^{2}$ Considero que la perspectiva de la gobernabilidad migratoria es una forma ideológica concreta que adopta la visión de Estado en materia de migraciones internacionales. Siguiendo los planteos teóricos de Bourdieu y Sayad acerca del Estado y el pensamiento de Estado (Bourdieu, 1997; Sayad, 1999), entiendo la visión de Estado que se produce en el terreno político de la migración como el conjunto de ideas y prácticas instituidas como visión dominante o hegemónica en la construcción de la figura social de la inmigración y los inmigrantes. De acuerdo a Bourdieu y Sayad, el pensamiento de Estado puede comprenderse como una forma de pensamiento (que involucra acción) producida por el Estado de manera relacional con otros actores sociales y políticos e interiorizada como visión dominante o hegemónica, a través de la cual se establecen determinados principios de visión y división del mundo social como legítimos.

${ }^{3}$ En los últimos años ha surgido una interesante corriente de análisis crítico de este nuevo régimen global de control de las migraciones y de los actores que lo promueven. Véase, por ejemplo, Düvell (2003) y, más recientemente, Andrijasevic y Walters (2010) y los artículos contenidos en Geiger y Pécoud (2010).

${ }^{4}$ Geiger y Pécoud (2010) atribuyen la noción de migration management a Bimal Ghosh, quien durante los años noventa asistió como consultor de Naciones Unidas y de la OIM diversos proyectos referidos a las migraciones internacionales, entre ellos el NIROMP (New International Regime for Orderly Movements of People) que sirvió de base para la estrategia de la OIM.

${ }^{5}$ Para mayores detalles sobre la cuestión migratoria en los procesos de integración subregional y en los foros consultivos regionales mencionados, véase Mármora (2003), Novick (2005), Stuhldreher (2006), Martínez Pizarro y Stang (2006) y Ramírez y Alfaro (2010), entre otros. Para una aproximación crítica a la relación entre las migraciones internacionales y los bloques de integración regional como el Mercosur y la CAN, véase Romano (2009) y Stang (2009) respectivamente. Para una revisión retrospectiva de las respuestas estatales a las migraciones en los países andinos, véase Araujo y Eguiguren (2009).

${ }^{6}$ Sobre la gobernabilidad migratoria en América Latina, véase Mármora (1996, 2003) y Martínez Pizarro (2001). Véase Ortiz (2011) y Santi (2011) para una lectura crítica acerca de la "gobernabilidad migratoria" en los espacios regionales sudamericano e iberoamericano. Kron (2011), por su parte, realiza un sugerente análisis del "paradigma de la gestión migratoria” (migration management) en Norte y Centroamérica.

${ }^{7}$ De acuerdo a Mármora (2003), la CSM, cuya formación responde a los compromisos asumidos por los gobiernos en la Conferencia Mundial de Población de El Cairo (1994), es considerado también como un intento de consolidación, ampliación y programación sistemática de los desarrollos alcanzados en los procesos de integración subregional en América del Sur, tanto en la CAN como en el Mercosur.

${ }^{8}$ Para otros trabajos que desarrollan esta línea de indagación, véase también Magliano y 
Romano (2009) y Magliano y Clavijo (2011), Ortiz (2011) y Santi (2011).

${ }^{9}$ Informes sobre las migraciones internacionales en el mundo como el de la Global Commission on International Migration (GCIM) de Naciones Unidas pretenden mostrar que son producto del consenso obtenido a través de mecanismos "participativos" como consultas a funcionarios y técnicos de organismos de Estados nacionales, representantes de asociaciones de migrantes, activistas o miembros de organizaciones civiles y eclesiásticas, académicos de centros de investigación, etcétera.

${ }^{10}$ La experiencia argentina reciente, por ejemplo, es presentada en el ámbito regional por representantes de diversas agencias internacionales -entre ellas la OIM- como modelo a imitar.

${ }^{11}$ En este sentido, también es preciso tener en cuenta que la entrada en vigor de las convenciones internacionales depende de la ratificación de los Estados nacionales.

${ }^{12}$ La figura del balance contable aplicada a la inmigración, que critica Sayad (1998), muestra la función que se le atribuye a los inmigrantes y el significado que se desea reservar a la inmigración: la inmigración y los inmigrantes sólo tienen sentido mientras la contabilización (o comparación) de costos y ventajas deje un saldo positivo. Esta visión, en términos ideales, supone una maximización de las ventajas (principalmente económicas) de la inmigración y a la vez una minimización de los costos (fundamentalmente sociales y culturales) de la presencia de los inmigrantes. Este esquema, contenido expresamente en la perspectiva de la gobernabilidad migratoria, asume implícitamente la rentabilidad como criterio para determinar en qué medida la presencia del inmigrante es o no legítima.

${ }^{13}$ Uno de los informes anuales del CELS sobre la situación de los derechos humanos en la Argentina (CELS, 2001) denuncia que en el año 2000 la DNM rechazó solicitudes de radicación de personas con discapacidad y decidió, arbitrariamente, no renovar las radicaciones precarias de 3.000 inmigrantes de nacionalidad boliviana, declarando "ilegal" su permanencia y disponiendo su expulsión en algunos casos. También denuncia la violación del principio de gratuidad del régimen administrativo en detrimento de los inmigrantes en relación a la igualdad ante la ley. Por otra parte, cabe señalar que durante este período se realizaron expulsiones de manera permanente. Entre los años 2000 y 2002 hubo aproximadamente 11.685 expulsiones. Según cifras de la Dirección de Migraciones y del CELS, los informes de la Gendarmería Nacional señalaban 1.600 expulsiones en 2000, 3.300 en 2001 y 1700 hasta octubre de 2002 (estos datos no incluyen las deportaciones de personas con antecedentes penales). La Prefectura Naval, por su parte, registra 1.505 expulsiones en 2000, 2.098 en 2001 y 1.482 hasta octubre de 2002. La colectividad paraguaya fue la más afectada por estas medidas: el número de deportaciones oscilaba entre 80 y 200 ciudadanos por mes.

${ }^{14}$ En los diversos documentos también se utilizan nociones como "mirada”, “enfoque” o “abordaje”.

${ }^{15}$ MRECIyC, Encuentro Iberoamericano sobre Migraciones y Desarrollo, Madrid, 2006. Sobre el "nuevo paradigma" en la política migratoria argentina, véase también Courtis y Pacecca (2007).

${ }^{16}$ En este contexto, si bien el ámbito estatal ha sido históricamente el espacio reservado para el tratamiento de esta materia, en los últimos tiempos, según Sassen, asistimos a una 
“transnacionalización de facto” en el manejo de los asuntos migratorios, lo cual implica que el Estado no define exclusivamente las políticas migratorias en el marco de sus fronteras nacionales, sino mediante la actuación de diversos actores sociales y políticos, sean de carácter nacional o transnacional, en espacios locales o supranacionales. En este sentido, la internacionalización del régimen de derechos humanos estaría afectando cada vez más la política migratoria (Sassen, 2003).

${ }^{17}$ Es preciso señalar que cuando los funcionarios de la DNM se refieren en sus exposiciones o intervenciones públicas a la "gobernabilidad de las migraciones" lo hacen para indicar el objetivo que se persigue y no para enunciar la perspectiva adoptada.

${ }^{18}$ Durante la entrevista, el funcionario establece este año como corte, pero no en respuesta directa a una pregunta, sino mientras yo retomaba su planteo referido a la experiencia de los noventa y la situación de principios de la década en materia migratoria. Al referirme a los “comienzos de esta década”, el funcionario agrega: “Sí, 2002, más o menos” (E-AR-1-05).

${ }^{19}$ He utilizado en esta ocasión la denominación que usó por primera vez para nombrar esta nueva perspectiva que habría adoptado paulatinamente el Estado nacional sobre las migraciones internacionales. De todas maneras, a lo largo de las dos entrevistas realizadas, el funcionario se refiere indistintamente a la "gobernabilidad de las migraciones", la "gobernabilidad de los procesos migratorios" o la "gobernabilidad de los flujos migratorios", caracterizándola como "doctrina” o "corriente”.

${ }^{20}$ Así lo expresa: “A mí me parece que no es casualidad, que hay un proceso de maduración que cae... que estaba dando vueltas y de golpe hay una instancia histórica, un momento histórico donde esta pieza calza y va para adelante. Y ahora hay un proceso de enraizado... en los funcionarios, en la opinión pública...” (E-AR-2-07).

${ }^{21}$ Entre ellos nombra a la funcionaria de la DNM, Adriana Alfonso. Opina que fue "el motor de todo este tema en el Mercosur, en la soledad más absoluta, empujando, mostrando y convenciendo" (E-AR-2-07).

${ }^{22}$ El funcionario destaca especialmente el papel que tuvo un consultor de alto rango de la OIM, Lelio Mármora, en la formación de estos funcionarios y le atribuye "mucha importancia” a su persona y a la labor que desempeñó en el desarrollo de la política migratoria regional. Es muy ilustrativo el hecho de que durante la VIII Conferencia Sudamericana sobre Migraciones (CSM), realizada en Montevideo en el año 2008, Lelio Mármora fuera presentado por Eugenio Ambrossi, representante regional de la OIM para el Cono Sur, como el padre de la CSM.

${ }^{23}$ Como muestra Dale (1999) en su análisis sobre los efectos de la globalización en las políticas educativas nacionales, cada agencia internacional desarrolla distintas estrategias y mecanismos de negociación. En su artículo, propone una tipología de estos mecanismos: imposición, instalación de interdependencia, estandarización, diseminación, armonización, aprendizaje y préstamo.

${ }^{24}$ El director de la DNM, Ricardo Rodríguez, expresó en esta ocasión: "Las corrientes migratorias no se paran con el Ejército, la decisión humana no se puede detener con el Ejército, la única forma es direccionarlas. Siempre comparo las corrientes migratorias con el agua: por más que se construyan diques, por algún lado natural va a buscar el ingreso. Y cuando uno pide requisitos extremos e impide los ingresos, lo único que genera es el nego- 
cio de los malos intencionados que viven de las necesidades humanas. Lamentablemente existe esa parte de la naturaleza humana que nos lleva a eso.” (Ricardo Rodríguez, Cámara de Diputados de la Nación, Buenos Aires, 2005). Esta metáfora también fue utilizada por el director general de Asuntos Consulares del Ministerio de Relaciones Exteriores y Culto, Raúl Martínez Camadro, durante su visita a la Comisión de Población y Recursos Humanos de la Cámara de Diputados de la Nación en el año 2002 en el marco de los intercambios mantenidos acerca de la nueva ley de migraciones. En dicha oportunidad expresó: "Es cierto que históricamente ha existido siempre un flujo y reflujo de corrientes migratorias. Obviamente, el tema de las migraciones es casi como el del agua, en el sentido de que uno puede intentar poner una contención. En efecto, se puede establecer una ley dura, que fije el criterio de la migración cero, como ocurre en los Estados Unidos respecto de los mexicanos; se puede pensar en electrificar la frontera, poner un vallado o utilizar el río. También se puede establecer la idea de la migración selectiva: piden ingenieros, cocineros o gerentes de hotel, como hace Canadá u otros países. Pero lo cierto es que, si bien el derecho legisla, no se puede cubrir toda la realidad, que al igual que el agua, cuando encuentra una piedra da la vuelta por el costado. Es muy difícil estar siempre alerta.” (énfasis propio).

${ }^{25}$ Ricardo Rodríguez, Comisión de Población y Recursos Humanos, Cámara de Diputados de la Nación, Buenos Aires, 2005.

${ }^{26}$ Según Sayad (1998:15), el discurso sobre el inmigrante y la inmigración establece una relación indefectible con otros objetos o problemas para poder hablar de su objeto: sólo a través de los diferentes problemas a los cuales son asociados es que los inmigrantes pueden ser "nominados, captados y tratados". Aquí los "problemas" son entendidos tanto como "dificultades”, "disturbios” o "daños” y como "problemática constituida de forma crítica en relación a un objeto que crea necesariamente un problema” y que debe su existencia a los problemas que representa para la sociedad.

${ }^{27}$ El control de la migración basado en la biometría ha abierto un nuevo capítulo en el control de la "ilegalidad migratoria". Algunos países sudamericanos ya han comenzado a utilizarla. En la Argentina, se creó por decreto en el año 2011el Sistema Federal de Identificación Biométrica para la Seguridad (SIBIOS). Este sistema se ha difundido (escasamente) bajo un elocuente lema: "Si nos conocemos mejor, nos cuidamos más”. 


\section{Bibliografía}

Andrijasevic, Rutvica y William Walters (2010), “The International Organization for Migration and the international government of borders”, en Environment and Planning D: Society and Space, Vol. 28, Nº 6.

Araujo, Lorena y María Mercedes Eguiguren (2009), “La gestión de la migración en los países andinos: entre la securitización y los vínculos diaspóricos”, en Andina Migrante, № 3.

Bourdieu, Pierre (1997), Razones prácticas. Sobre la teoría de la acción. Anagrama, Barcelona.

CELS (2001), Informe sobre la situación de los Derechos Humanos en Argentina: enero-diciembre 2000. Catálogos, Buenos Aires.

Courtis, Corina y María Inés Pacecca (2007), “Migración y derechos humanos: una aproximación crítica al 'nuevo paradigma' para el tratamiento de la cuestión migratoria en Argentina”, en Revista Jurídica de Buenos Aires.

Dale, Roger (1999), "Specifying globalization effects on national policy: a focus on the mechanisms”, en Education Policy, Vol. 14, № 1.

De Genova, Nicholas (2002), “Migrant 'Illegality’ and Deportability in Everyday Life”, en Annual Review of Anthropology, № 31.

Domenech, Eduardo (2007), “La agenda política sobre migraciones en América del Sur: el caso de la Argentina”, en Revue Européenne des Migrations Internationales, Vol. 23, Nº 1 .

Ídem (2008), “La ciudadanización de la política migratoria en la región sudamericana: vicisitudes de la agenda global”, en Novick, Susana, comp.; Las migraciones en América Latina. Políticas, culturas y estrategias. CLACSO / Catálogos, Buenos Aires.

Düvell, Franck (2003), “The globalisation of migration control”. En OpenDemocracy [Versión electrónica en http://www.opendemocracy.net/ people-migrationeurope/article_1274.jsp visitada en Octubre, 2009]

Ídem (2008), “Clandestine migration in Europe”, en Social Science Information, Vol. 47, $\mathrm{N}^{\circ} 4$.

Geiger, Martin y Antoine Pécoud (2010), The Politics of International Migration Management. Palgrave Macmillan, Houndmills/Basingstoke.

Ghosh, Bimal (2008), “Derechos humanos y migración: el eslabón perdido”, en Migración y Desarrollo, N 10. 
Guimarães, Samuel (2005), Cinco siglos de periferia. Una contribución al estudio de la política internacional. Prometeo, Buenos Aires.

Hansen, Randall (2010), An Assessment of Principal Regional Consultative Processes on Migration, IOM Migration Research Series, No 38. Ginebra: OIM.

Kron, Stefanie (2011), “Gestión migratoria en Norte y Centroamérica: manifestaciones y contestaciones”, en Anuario de Estudios Centroamericanos, $\mathrm{N}^{\circ} 37$.

López Sala, Ana María (2005), “La inmigración irregular en la investigación sociológica”, en Dirk Godenau, Vicente Manuel Zapata Hernández, coords.; La inmigración irregular: aproximación multidisciplinar. Cabildo Insular de Tenerife, Tenerife.

Magliano, María José y Silvina Romano (2009), “Migración, género y (sub)desarrollo en la agenda política internacional: una aproximación crítica desde la periferia sudamericana”, en Cuadernos del Cendes, Año 26, $\mathrm{N}^{\circ} 72$.

Magliano, María José y Janneth Clavijo (2011), “La trata de personas en la agenda política sudamericana sobre migraciones: la securitización del debate migratorio”, en Análisis Político, N 71.

Mármora, Lelio (1996), “El desafío de las políticas migratorias; su gobernabilidad”, en Dora Celton, coord.; Migración, integración regional y transformación productiva. CEA-UNC, Córdoba.

Ídem (2002), Las políticas de migraciones internacionales. Paidós/OIM, Buenos Aires.

Ídem (2003), “Políticas migratorias consensuadas en América Latina”, en Estudios Migratorios Latinoamericanos, Año 17, No 50.

Ídem (2004), “Las leyes de migraciones como contexto normativo (De la “Ley Videla” a la Ley de Migraciones 25.871)” en Rubén Giustiniani, comp., Migración: un derecho humano. Prometeo, Buenos Aires.

Martínez Pizarro, Jorge (2001), “Reflexiones sobre la gobernabilidad de la migración internacional en América Latina”, en Migraciones Internacionales, Vol. I, $\mathrm{N}^{\mathrm{o}} 1$.

Martínez Pizarro, Jorge y Fernanda Stang (2006), “El tratamiento migratorio en los espacios de integración subregional sudamericana”, en Papeles de Población, $\mathrm{N}^{\mathrm{0}} 48$.

Mezzadra, Sandro (2012), “Capitalismo, migraciones y luchas sociales. La mirada de la autonomía”, en Nueva Sociedad, № 237. 
Novick, Susana (2005), "La reciente política migratoria en el contexto del Mercosur”, en Susana Novick, Alejandro Hener y Pablo Dalle; El proceso de integración Mercosur: de las políticas migratorias y de seguridad a las trayectorias de los inmigrantes, Documentos de Trabajo del Instituto de Investigaciones Gino Germani de la Universidad de Buenos Aires, $N^{\circ} 46$.

Ortiz, Claudia (2011), “Algunas dimensiones del ideario de la gobernabilidad migratoria: el proceso de institucionalización de la Conferencia Sudamericana de Migraciones”, en Cuadernos de H Ideas, Vol. 5, $\mathrm{N}^{\circ} 5$.

Ramírez, Jacques y Yolanda Alfaro (2010), “Espacios multilaterales de diálogo migratorio: el proceso Puebla y la Conferencia Sudamericana de Migración”, en Andina Migrante, № 9.

Romano, Silvina (2009), “Integración económica, desarrollo y migraciones en el MERCOSUR. Una aproximación crítica”, en Eduardo Domenech, coord.; Migración y política. El Estado interrogado. Procesos actuales en Argentina y Sudamérica. UNC, Córdoba.

Santi, Silvana (2011), “¿Beneficios para todos? Crisis, desarrollo, y gobernabilidad, en la agenda política iberoamericana sobre migraciones”. Ponencia presentada en el IV Congreso de la Red Internacional de Migración y Desarrollo. Crisis global y estrategias migratorias: hacia la redefinición de las políticas de movilidad, Quito, Ecuador, 18-20 de mayo de 2011.

Sassen, Saskia (2003), Los espectros de la globalización. Fondo de Cultura Económica, Buenos Aires.

Sayad, Abdelmalek (1998), A imigracão ou os paradoxos da alteridade. USP, São Paulo.

Ídem (1999), La double absence. Des illusions aux souffrances de l’immigré. Seuil, Paris.

Stang, Fernanda (2009), “El migrante unidimensional. El dispositivo jurídico migratorio en la Comunidad Andina de Naciones”, en Eduardo Domenech, coord.; Migración y Política: el Estado interrogado, Procesos actuales en Argentina y Sudamérica. Córdoba: UNC.

Stuhldreher, Amalia (2006), “La problemática de la migración en América Latina: ¿De enfoques intergubernamentales hacia la transnacionalización de la política migratoria?” en Wehr, Ingrid, ed.; Un continente en movimiento: Migraciones en América Latina. Madrid/Frankfurt: Iberoamericana/Vervuert.

Torpey, John (2000), The Invention of the Passport. Survillance, Citizenship 
Polis, Revista Latinoamericana, Volumen 12, No 35, 2013

and the State. Cambridge University Press, Cambridge.

Recibido: 18.06.2013

Aprobado: 24.07.2013 